\title{
Erratum: Report of the 2005 RSPCA/UFAW Rodent Welfare Group meeting
}

Penny Hawkins, BSc, PhD (Secretary), Leigh M. Felton, BSc, PhD, Pascalle van Loo, PhD, Mark Maconochie, BSc, PhD, Dominic J. Wells, MA, VetMB, PhD, Ngaire Dennison, MA, VetMB, Robert Hubrecht, BSc, PhD \& Maggy Jennings, BSc, PhD Lab Anim. (NY), 35(9), 29-38 (2006).

In the section entitled, "Changes in burrowing and nesting behavior as early indicators of sickness in mice," an editorial error incorrectly rendered a sentence about quantification of burrowing behavior as "the average mouse will consume the pellets in a tube in two hours." This wording incorrectly indicates that the mice eat the pellets; in fact, the sentence should read, "the average mouse will empty the pellets from a tube in two hours." The error has been corrected in the PDF version of the article. 